\title{
Traits of the entomopathogenic nematode, Heterorhabditis bacteriophora (Hb-EG strain), for potential biocontrol in strawberry fields
}

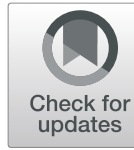

\author{
Ibrahim E. Shehata', Mostafa M. A. Hammam², Fahiem E. El-Borai ${ }^{3,4}$, Larry W. Duncan³ and \\ Mahfouz M. M. Abd-Elgawad ${ }^{*}$
}

\begin{abstract}
Entomopathogenic nematodes (EPNs) can provide a substantial control, especially of the root feeding larval pests. The objective of the present study was to examine beneficial traits of an indigenous entomopathogenic nematode species, Heterorhabditis bacteriophora Poinar (Hb-EG strain), and to identify superior biocontrol candidates for suppression of the scarab beetle Temnorhynchus baal (Reiche \& Saulcy) (Coleoptera: Scarabaeidae: Dynastinae) larvae as serious pests of strawberry in Egypt. The nematodes were applied to infect the greater wax moth, Galleria mellonella L. cadavers, to represent natural emergence from the host in laboratory and under field conditions. Its average yield was 49604 infective juveniles (IJS) per G. mellonella larva. Overall averages of nematode-induced mortality in G. mellonella larvae were $(4.63,3.12$, and 1.92$)$ at 4, 8, and 12 weeks, respectively, after continuous weekly baiting with 5 cadavers. Nematode capability for infection and reproduction ranged from 72 to $26 \%$ one to five months, respectively, after field inoculation of the infected larvae into the strawberry rhizosphere. The number of IJs, moved to the North of the rhizosphere, was significantly $(P \leq 0.05)$ less than that moved to the South or the East as reflected by the numbers of infected insects. The factors that may have a marked influence on EPN foraging behavior, persistence, and movement direction with implications for harnessing them as biological pest control agents were discussed.
\end{abstract}

Keywords: Biological control, Entomopathogenic nematodes, Indigenous traits, Strawberry, Egypt

\section{Background}

White grubs (larvae of scarab beetles) are serious pests of strawberry (Shehata et al. 2019). Control recommendations for the white grubs currently consist solely of applications of chemical insecticides (El-Shemy et al., 2013). Due to the health hazards and environmental pollution problems associated with such chemicals, research on developing alternative and safe control strategies is desperately needed (Trdan et al. 2019). Entomopathogenic nematodes (EPNs), in the two families Steinernematidae and Heterorhabditidae, are potential environmentally friendly biological alternatives.

\footnotetext{
* Correspondence: mahfouzian2000@yahoo.com

${ }^{2}$ Plant Pathology Department, National Research Centre, El-Behoos St., Dokki, Giza 12622, Egypt

Full list of author information is available at the end of the article
}

They possess virtually many attributes of ideal biological control agents. Dozens of important insect pests are susceptible yet non-target populations are mostly undisturbed (Abd-Elgawad et al. 2017). Despite their high pathogenicity to insects, their lack of threat to the environment facilitated their commercialization without registration requirements in many countries.

Therefore, a number of studies have examined the persistence of these biological control agents (Khan and Javed 2018 and Shehata et al. 2019). Interestingly, to survive in the native soil of the tested strain, EPNs possess a motile infective stage (IJs), which occupies soil habitats until they infect a host. Thus, critical points in the EPNs' life history are their reproductive capacity within the host, persistence, dispersal, and movement direction. 
Such beneficial traits have been reported to differ among strains/species (Bal et al., 2017; Hussaini 2017 and Ruan et al. 2018). Their dispersal has been studied in terms of biotic and abiotic factors that affect nematode travel within the soil profile, but a dearth of information related to foraging patterns and movement direction, particularly in the absence of their hosts' remains.

The objective of the present study was to examine beneficial traits of an indigenous strain of Heterorhabditis bacteriophora Poinar that has a high potential for biocontrol of white grub in the strawberry fields.

\section{Materials and methods}

\section{Insect culture and nematode strain}

Last instar larvae of the greater wax moth, Galleria mellonella (L.), reared on artificial diet according to AbdElgawad (2001), and were obtained from the Nematology Laboratory (National Research Centre, Egypt). Heterorhabditis bacteriophora (Hb-EG strain) was obtained from USA-Egyptian Mutual Research Project. The nematode strain was reared at $\approx 25{ }^{\circ} \mathrm{C}$ in the G. mellonella larvae according to procedures described in Woodring and Kaya (1988).

\section{Laboratory tests}

Heterorhabditis bacteriophora-infected G. mellonella larvae were also used for soil inoculation under laboratory and field conditions. To prepare cadavers, 400 healthy G. mellonella last instar larvae were equally released into $2012-\mathrm{cm}$ petri dishes (sterilized with $70 \%$ alcohol and lined with filter paper): 20 larvae per dish. One milliliter of nematode suspension of the Egyptian strain was sprayed directly into the dish, using a plastic syringe; the nematodes were counted so that about 200 infective juveniles (IJs) were used per each insect larva. All sprayed dishes were incubated at $25 \pm 1{ }^{\circ} \mathrm{C}$ for 3 days. Then, 200 infected larvae, which appeared to have active infection, immobile with reddish-brown color, were selected. These selected larvae were divided into 3 groups, i.e., 20, 30, and 150 infected hosts (G. mellonella). The first 20 cadavers were placed singly on 20 White traps (White, 1929 ) at the rate of one cadaver per $5-\mathrm{cm}$ petri dish to measure the reproductive capacity (nematode yield per insect) of Hb-EG strain (Woodring and Kaya 1988). The mean number of IJs emerged from $H$. bacteriophora-infected G. mellonella larvae was compared with IJs for each of 2 groups, comprising 23 and $15 \mathrm{H}$. indica populations emerging from the scarab grub, Temnorhynchus baal (Reiche \& Saulcy) (Coleoptera: Scarabaeidae: Dynastinae) in a previous study (Shehata et al. 2019), using the two-tailed Student's $t$ test. Transformed nematode counts, $\log _{10}(\mathrm{X})$, were subjected to the analysis because using original counts of IJs with aggregated distribution violates assumptions necessary for parametric statistical analysis (Ferris, 1974).

Other 30 cadavers were used to measure nematode persistence in a laboratory test. The soil was transferred to the laboratory from a strawberry field at El-Dare Village, Tokh Centre, El-Qalioubia governorate, Egypt, using a hand shovel up to $10 \mathrm{~cm}$ of soil depth. The soil samples were sterilized in the oven at $320{ }^{\circ} \mathrm{C}$ for $1 \mathrm{~h}$ to kill all live organisms; thereafter, all samples were moistened by addition of $200 \mathrm{ml}$ of distilled water for each $\mathrm{kg}$ of the soil. Experimental units consisted of plastic semicone cups $(12.8 \mathrm{~cm}$ diam., $9 \mathrm{~cm}$ deep) filled to a depth of $\approx 8 \mathrm{~cm}$ with the loamy sand (sand 82.8 , silt 6 , clay 11.2 , $\mathrm{pH} 7.8, \mathrm{CaCO} 313.8 \%$, OM 8.7\%) soil (about $1 \mathrm{~kg} / \mathrm{cup}$ ). Two of the infected larvae were placed randomly within each of 15 cups at $5 \mathrm{~cm}$ away of the soil surface and kept at $25 \pm 2{ }^{\circ} \mathrm{C}$ and $70 \% \mathrm{RH}$ during the extraction cycles. Ten days after adding the infected insects, 5 live last instar G. mellonella larvae per cup were similarly added and examined after 1 week in order to (i) isolate any of the 5 added insects, which showed symptoms of EPN infection. These cadavers were transferred to White traps to fulfill Koch's postulates (Pelczar and Reid, 1972) and/ or (ii) discard the other dead insects. A new Galleria baiting cycle began with replacing the infected cadavers/ dead insects by new living G. mellonella larvae. Examining larval mortality to be replaced by living ones occurred weekly for 12 weeks. Suspect cadavers that failed to produce infectives were considered negative. An analysis of variance (ANOVA), followed by Duncan's new multiple range test (DNMRT), was used to compare the weekly data of nematode persistence among the 12 weeks. Also, data of the 4 consecutive weeks were pooled together so that mean numbers of infected larvae after 4, 8, and 12 weeks (almost 1, 2, and 3 months) of exposure in the soil were also compared.

\section{Field experiments}

Likewise, nematode persistence was determined by measuring mortality of G. mellonella larvae over time in the above-mentioned strawberry "cv. Festival" field (longitude of $31.21^{\circ}$ North latitude, $30.18^{\circ}$ East longitude, and 180 feet elevation). The strawberry was transplanted on beds on 20 September 2018. Each bed $(25 \mathrm{~m}$ in length, $95 \mathrm{~cm}$ in width, $25 \mathrm{~cm}$ height) had 2 longitudinal tubes to irrigate 4 strawberry rows. The field was not previously treated with any fumigants or insecticides. It had previously negative samples for EPNs. Plants in a row were spaced $20 \mathrm{~cm}$ apart. All agricultural practices were carried out as recommended (El-Shemy et al. 2013). On 7 November 2018, 30 consecutive strawberryplanted beds were selected. Ten infected larvae of the remaining 150 ones were equally placed inside every 
other selected bed, i.e., 15 beds ( 2 larvae per a root system of every other plant in a randomly selected row of a bed). Six days post EPN infection, the infected larvae were inoculated at $10 \mathrm{~cm}$ deep in the rhizosphere soil where each 2 larvae were placed in the 2 opposite directions around a root system. So, inoculated root systems were spaced $40 \mathrm{~cm}$ apart (10 larvae/1.6 m long row in each bed). Five soil samples were taken from each bed (a sample per an inoculated root system) at 1, 2, 4, and 5 months after inoculating the cadavers into the field beds. Each $0.5 \mathrm{~kg}$ sample was put in cups of half the size of the above-mentioned ones, baited with 5 live G. mellonella larvae per cup and subjected to the similar abovementioned laboratory conditions and procedures. The larvae, which had EPN infection after a week of baiting, were recorded and transferred to White traps to confirm infection.

Five of the inoculated beds that had the highest insect mortality rates, due to EPN infection after one month of inoculation, were selected for exploring the direction of EPN movement in the soil after insect inoculation. Additional 4 samples were taken per an inoculated plant from the 4 directions (South, North, West, and East), each about $5-15 \mathrm{~cm}$ away from the center of the root system at 5-15 cm depth. Three inoculated plants were randomly selected for sampling per bed by hand shovel at about 5,8 , and 16 weeks post insect inoculation. At each time, $0.5 \mathrm{~kg}$ sample was put in a cup $(12.8 \mathrm{~cm}$ diam., $4.5 \mathrm{~cm}$ deep) with 5 live G. mellonella larvae and transferred to the laboratory as mentioned above. So, 12 cups (samples) per bed ( 3 plants $\times 4$ directions per each plant) were taken. The larvae which had EPN infection after a week of baiting were similarly transferred to White traps. Means of the infected larvae for each of the above-mentioned samples were calculated and used as an indicator for persistence and direction in movement of $\mathrm{Hb}$-EG strain in the soil under strawberry field conditions. Similar statistical comparison among the means was also done.

\section{Results and Discussion}

The average ( \pm standard deviation) yield of IJs per $G$. mellonella larva was $49604 \pm 20257$ herein. The corresponding average of 15 populations (Shehata et al., 2019) related to Egyptian $H$. indica IJs emerged from the infected scarab grub, T. baal (Coleoptera: Scarabaeidae), in sandy soil, 46,960 IJs/grub, was not significantly $(P \leq$ $0.05)$ different from that of $\mathrm{Hb}-\mathrm{EG}$ strain reported herein $(t=0.99 ; d f=33)$. Yet, the average $(36,502 \mathrm{IJS} /$ grub) of other 23 Egyptian $H$. indica populations (Shehata et al. 2019) in loamy sand soil was significantly different $(t=2.05 ; d f=41)$ from that of Hb-EG strain reported herein. However, when these 2 groups of populations were combined together (38 populations), the average (41,000 IJs/grub) of their released IJs was lower $(P \leq 0.05)$ than that of Hb-EG strain researched herein $(t$ $=4.05 ; d f=56)$. This difference is possibly due to the used insect host, EPN species/strain, reproductive capacity, and/or genetic constitution, given the other aspects of the general identical procedure applied in the laboratory for IJs extraction and counting.

Insect mortality caused by Hb-EG strain was the greatest after the first baiting, but began to decrease over time (Fig. 1). Interestingly, some successive weeks had significant differences among numbers of the infected host such as weeks 5,6 , and 7 , contrary to weeks 8,9 , 10 , and 11 . This might be due to the relatively low numbers of IJs over time. Overall averages ( \pm standard

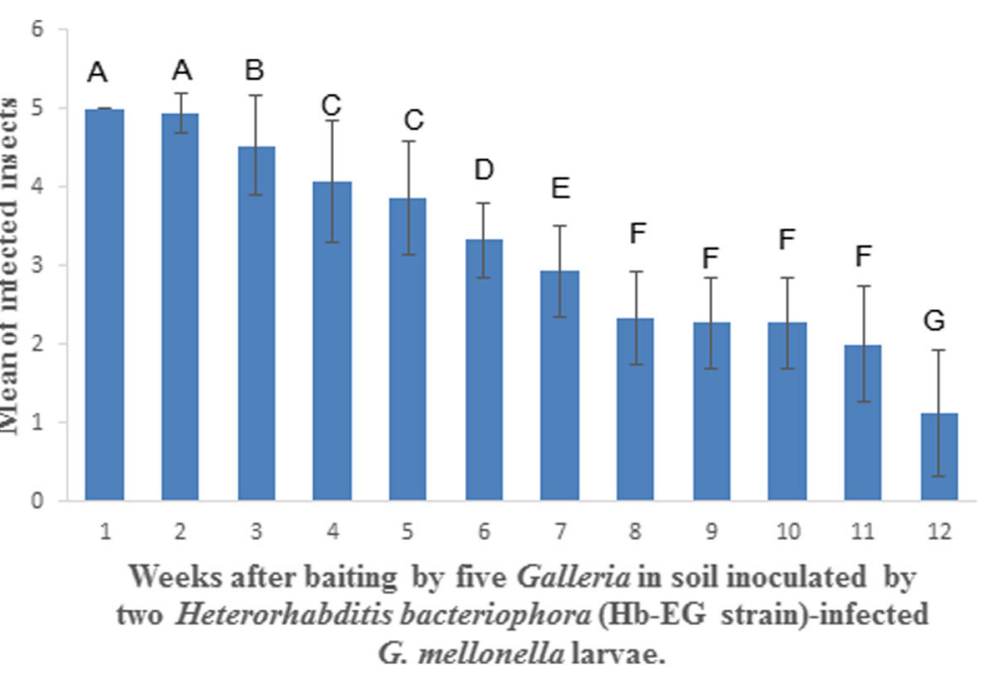

Fig. 1 Heterorhabditis bacteriophora (Hb-EG strain) persistence measured by ability to infect G. mellonella larvae in soil at extended baiting times. Means ( \pm SD) of five insects per cup for 15 replicates (cups). Different letters above bars indicate statistical significance $(P \leq 0.05)$ using DNMRT 
deviations) of nematode-induced mortality in G. mellonella larvae were $4.63 \pm 0.36$ (for combined $1-4$ weeks), $3.12 \pm 0.47$ for $5-8$ weeks, and $1.92 \pm 0.62$ for $9-12$ weeks after the start of baiting, respectively. Their corresponding percentages were $92.67,62.33$, and $38.33 \%$, respectively. Nematode persistence, measured by the ability to infect G. mellonella larvae in soil over these baiting times, differed significantly $(P \leq 0.0001)$ among the 3 periods. Shehata et al. (2019) also found that the persistence of $H$. indica populations in the soil varied greatly concerning their total IJ numbers collected 10, 18,26 , and 30 days post-inoculation in sandy or loamy sand soil.

In contrast, under field condition, nematode capability for infection and reproduction ranged from 72 to $26 \%$, 1-5 months post its inoculation via the infected wax moth larvae in the strawberry rhizosphere, respectively (Fig. 2). Obtained results showed that 92.7 and $62.3 \%$ of the exposed larvae were infected under laboratory conditions compared to only 72 and $50.4 \%$ in the field one and 2 months after inoculations, respectively. Generally, such an EPN efficacy gap is usually apparent between controlled and actual conditions due to harsh field events such as changes in soil temperature. Although EPN species/strains differ in their persistence in soil (e.g., Abd-Elgawad 2017a, b; Khan and Javed 2018 and Labaude and Griffin 2018), it is assumed that many biotic and physical factors can affect their persistence too. Biotic factors as availability of host insects (Hussaini, 2017), predation by other organisms such as mites and collembola (Wilson and Gaugler, 2004), and competition with other pathogens including even other EPNs

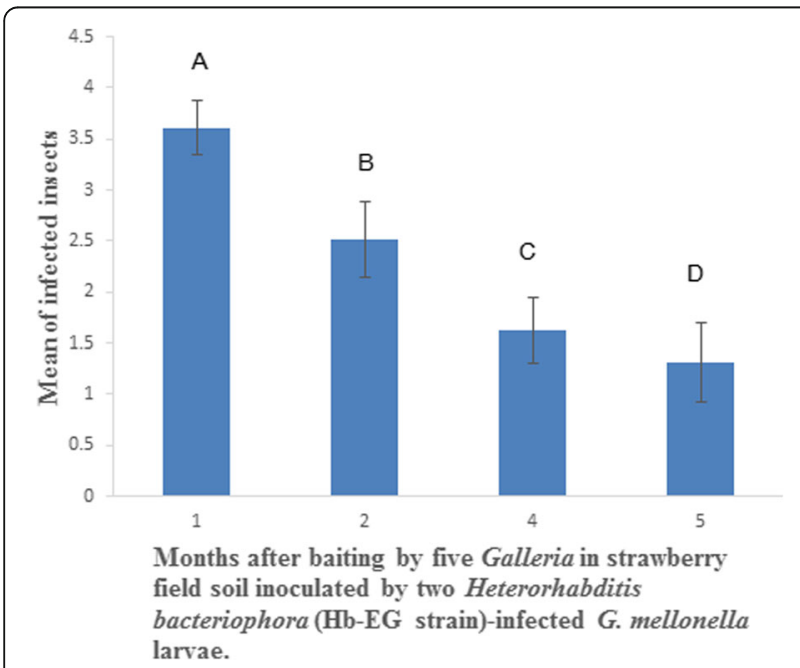

Fig. 2 Heterorhabditis bacteriophora ( $\mathrm{Hb}-\mathrm{EG}$ strain) persistence over 5 months. Means ( \pm SD) of 5 insects/cup (375 insects per 75 root systems; 5 cups per a bed) in 15 strawberry beds. Different letters above bars indicate statistical significance $(P \leq 0.05)$ using DNMRT
(Labaude and Griffin, 2018) can play a significant role. Physical factors such as soil mulching (Leite et al. 2015), soil type and moisture (Hussaini, 2017), application pattern of the introduced EPNs (Wilson et al., 2003), ultraviolet radiation, and desiccation and temperature extremes (Baiocchi et al. 2017) can also affect the EPN persistence. So, the significant $(P \leq 0.05)$ differences found between beds $(F=4.41 ; d f=14)$ in the infected numbers of insects are likely attributed to one or more of these factors and should be considered for more effective biocontrol potential (Abd-Elgawad, 2019).

Non-significant $(P \leq 0.05)$ differences were found among the 5 beds in the number of infected insects at each of the tested time, i.e., $5(F=0.28, P=0.89), 8(F=$ $0.19, P=0.94)$, and $16(F=1.38, P=0.26)$ weeks postinoculation $(d f=4)$. When the data of the 5 beds were combined together for statistical analyses, nonsignificant $(P \leq 0.05)$ difference in the mean numbers of infected insects was found between 5 th and 8th weeks $(\bar{x}$ $=0.65$ vs $0.9, n=75)$ post-inoculation. Yet, each of these numbers differed $(P \leq 0.05)$ from the mean number $(\bar{x}=$ $0.05, n=75)$ of the infected insects, 16 weeks postinoculation. Significant $(P \leq 0.05)$ differences were found among the cardinal directions of EPN movement (Fig. 3 ). The nematodes moved to the North had the least numbers. Their mean number over the 3 tested times was significantly $(P \leq 0.05)$ less than the corresponding number moved to the South or the East. Many factors may have a marked influence on EPN foraging behavior and movement direction. Kapranas et al. (2017) found that 2 levels of soil compaction and media with varying ratio of peat: sand could influence dispersal success of 3 EPN species, with different foraging strategies. Increasing peat content and compaction generally decreased IJ dispersal for Steinernema carpocapsae (ambusher), Heterorhabditis downesi (cruiser), and S. feltiae (intermediate). Of the 3 species, the least affected by peat content was $H$. downesi, whereas $S$. carpocapsae was the most adversely influenced by compaction. They found that dispersal of male and female IJs is also differentially affected by soil parameters and that this differentiation is species-specific. Other studies revealed that the EPNs respond directionally to insect host exudates (Dillman et al., 2012), plant volatiles (Jagodič et al., 2017), carbon dioxide (Ramos-Rodríguez et al. 2007), vibration (Torr et al. 2004), and magnetic and electric fields (Ilan et al. 2013). Likewise, various biotic and abiotic factors can affect movement behavior (Perony and Townsend, 2013) such as group size (Bonnell et al. 2013), environmental spatial structure and resource availability (Reeve and Cronin 2010), avoidance of predators (Beauchamp, 2017) and genetic diversity (Johnson et al. 2016). Bal and Grewal (2015) found that the cruise foraging H. bacteriophora differ in its dispersal and foraging behavior from 


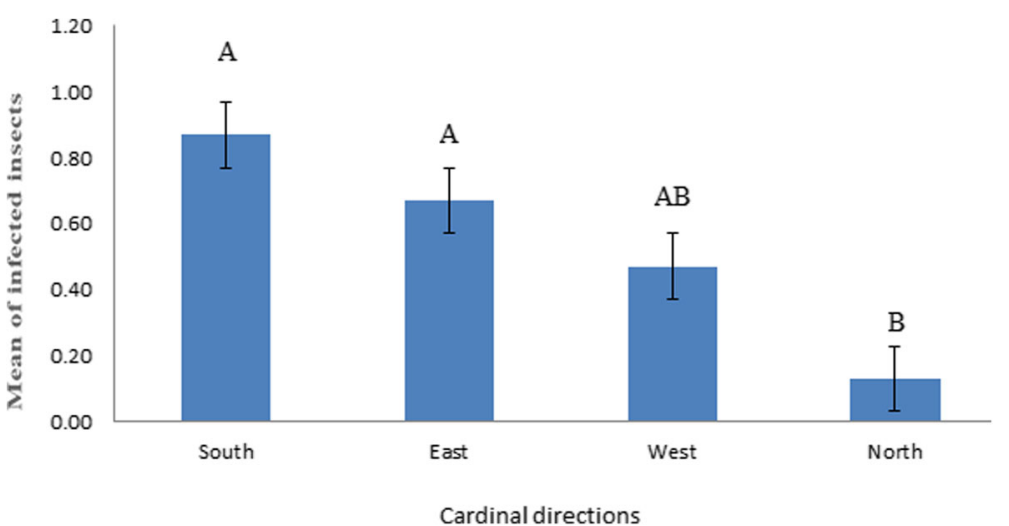

Fig. 3 Mean mortality of Galleria mellonella larvae (75 insects per 15 root systems in 5 strawberry beds for each direction in each of 3 times, a total of 900 baiting insects). Different letters above bars indicate statistical significance $(P \leq 0.05)$ using DNMRT

ambush foraging $S$. carpocapsae at the population level, and this behavior is affected by both the presence and absence of hosts and by their mobility. Ruan et al. (2018) reported that EPN dispersal continuously exhibited an aggregative pattern (independent movement was not observed). Given the narrow experimental range examined herein in addition to many unmeasured, hidden, physical, and biotic variables affecting EPN numbers, viability, and movement/dispersal, further studies on the effect of various edaphic and biotic factors on EPN efficacy and application for biological control are warranted with implications of using them for harnessing EPNs as biological pest control agents.

\section{Conclusions}

A beneficial trait of an indigenous nematode, Heterorhabditis bacteriophora Poinar (Hb-EG strain), was examined in various scenarios and compared with other heterorhabditis nematodes for the suppression of the scarab beetle larvae attacking strawberry plant roots in Egypt. The persistence of Hb-EG strain reported herein was significantly better than that of 23 Egyptian $H$. indica populations but did not differ from other 15 Egyptian $H$. indica populations. The infected insects at the North of the rhizosphere were significantly $(P \leq$ $0.05)$ less than that moved to the other directions. Further research is required to determine the cause of such trends as the variability in nematode persistence and cardinal directions as well as the applicability of these findings under different field conditions.

\section{Abbreviations}

DNMRT: Duncan's new multiple range test; EPN: Entomopathogenic nematode; IJs: Infective juveniles

\section{Acknowledgements}

This study was supported in part by the US-Egypt Project cycle 17 (no. 172) entitled "Preparing and evaluating IPM tactics for increasing strawberry and citrus production." This article is derived from the subject data funded in part by NAS and USAID, and that any opinions, findings, conclusions, or recommendations expressed in it are those of the authors alone, and do not necessarily reflect the views of USAID or NAS. Facilities offered by The National Research Centre are appreciated.

\section{Author's contributions}

Dr. Fahiem E. El-Borai helped Dr. Larry Duncan in the parts of work done at University of Florida.

\section{Funding}

This research was partially funded by US-Egypt Project fund via STDF for Project cycle 17 (no. 172) and by the National Research Centre.

\section{Availability of data and materials}

The datasets used and/or analyzed during the current study are available from the corresponding author on reasonable request.

Ethics approval and consent to participate

Not applicable

Consent for publication

Not applicable

\section{Competing interests}

The authors declare that they have no competing interests.

\section{Author details}

${ }^{1}$ Pests and Plant Protection Department, National Research Centre, El-Behoos St., Dokki, Giza 12622, Egypt. ${ }^{2}$ Plant Pathology Department, National Research Centre, El-Behoos St., Dokki, Giza 12622, Egypt. ${ }^{3}$ Citrus Research and

Education Center, Institute of Food and Agricultural Sciences, University of Florida, 700 Experiment Station Road, Lake Alfred, FL 33850, USA.

${ }^{4}$ Department of Plant Protection, Faculty of Agriculture, Zagazig University, Zagazig, Egypt.

Received: 14 January 2020 Accepted: 9 March 2020

Published online: 14 April 2020

\section{References}

Abd-Elgawad MMM (2001) Entomopathogenic nematode-host matching. Egypt J Agronematol 5:91-104

Abd-Elgawad MMM (2017a) Comments on the economic use of entomopathogenic nematodes against insect pests. Bull NRC 41(1):66-84

Abd-Elgawad MMM (2017b) Status of entomopathogenic nematodes in integrated pest management strategies in Egypt. In: Abd-Elgawad MMM, Askary TH, Coupland J (eds) Biocontrol agents: entomopathogenic and slug parasitic nematodes. CAB International, Wallingford, pp 473-501

Abd-Elgawad MMM (2019) Towards optimization of entomopathogenic nematodes for more service in the biological control of insect pests. 
Egyptian Journal of Biological Pest Control 29:77. https:/doi.org/10.1186/ s41938-019-0181-1

Abd-Elgawad MMM, Askary TH, Coupland J (eds) (2017) Biocontrol agents: entomopathogenic and slug parasitic nematodes. CAB Int, Wallingford, UK

Baiocchi T, Abd-Elgawad MMM, Dillman AR (2017) Genetic improvement of entomopathogenic nematodes for enhanced biological control. In: AbdElgawad MMM, Askary TH, Coupland J (eds) Biocontrol agents: entomopathogenic and slug parasitic nematodes. CAB International, Wallingford, pp 505-517

Bal HK, Grewal PS (2015) Lateral dispersal and foraging behavior of entomopathogenic nematodes in the absence and presence of mobile and non-mobile hosts. PLoS ONE 10(6):e0129887. https://doi.org/10.1371/journal. pone.0129887

Bal HK, Acosta N, Cheng Z, Grewal PS, Hoy CW (2017) Effect of habitat and soil management on dispersal and distribution patterns of entomopathogenic nematodes. Appl Soil Ecol 121:48-59

Beauchamp G (2017) The spatial distribution of foragers and food patches can influence antipredator vigilance. Behav Ecol 28:304-311

Bonnell TR, Dutilleul P, Chapman CA, Reyna-Hurtado R, Hernández-Sarabia RU, Sengupta R (2013) Analysing small-scale aggregation in animal visits in space and time: the ST-BBD method. Anim Behav 85:483-492

Dillman AR, Guillermin ML, Lee JH, Kim B, Sternberg PW, Hallem EA (2012) Olfaction shapes host-parasite interactions in parasitic nematodes. PNAS 109: E2324-E2333

El-Shemy AA, Khafagy YS, Al-Genteery AMM (2013) Cultivation and production of strawberry. Techn issue no. 9/2013, General Directorate of Agricultural Culture. Egyptian Ministry of agriculture, Giza, p 135 (in Arabic)

Ferris H (1974) Correlation of tobacco yield, value, and root-knot index with earlyto-midseason, and postharvest Meloidogyne population densities. J Nematol 6:75-81

Hussaini SS (2017) Entomopathogenic nematodes: ecology, diversity and geographical distribution. In: Abd-Elgawad MMM, Askary TH, Coupland J (eds) Biocontrol agents: entomopathogenic and slug parasitic nematodes. CAB Int, Wallingford, pp 88-142

Ilan T, Kim-Shapiro D, Bock CH, Shapiro Ilan DI (2013) Magnetic and electric fields induce directional response in Steinernema carpocapsae. Int J Parasitol 43 $781-784$

Jagodič A, Ipavec N, Trdan S, Laznik Ž (2017) Attraction behaviors: are synthetic volatiles, typically emitted by insect-damaged Brassica nigra roots, navigation signals for entomopathogenic nematodes (Steinernema and Heterorhabditis)? BioControl 62(4):515-524

Johnson D, Freiwald J, Bernardi G (2016) Genetic diversity affects the strength of population regulation in a marine fish. Ecology 97:627-639

Kapranas A, Maher AMD, Griffin CT (2017) The influence of organic matter content and media compaction on the dispersal of entomopathogenic nematodes with different foraging strategies. Parasitology 144:1956-1963

Khan YS, Javed N (2018) Entomopathogenic nematodes survey, persistence in soil, reproductive potential and their effects on Meloidogyne incognita. Egypt J Agronematol 17(2):109-120

Labaude S, Griffin CT (2018) Transmission success of entomopathogenic nematodes used in pest control. Insects 9:72. https://doi.org/10.3390/ insects9020072

Leite LG, Schmidt FS, Harakava R, Batista Filho A, Giometti FH C, Pietrobon T de C, Chacon-Orozco J (2015) The influence of mulch on the persistence of Steinernema brazilense (Nematoda: Steinernematidae) in sugarcane fields. Revista Colombiana de Entomología 41(2):176-179

Pelczar MJ, Reid RD (1972) Microbiology. USA, the McGraw-Hill Companies

Perony N, Townsend SW (2013) Why did the meerkat cross the road? Flexible adaptation of phylogenetically-old behavioral strategies to modern-day threats. PLoS ONE 8:e52834

Ramos-Rodríguez O, Campbell JF, Lewis EE, Shapiro-llan DI, Ramaswamy SB (2007) Dynamics of carbon dioxide release from insects infected with entomopathogenic nematodes. J Invertebr Pathol 94:64-69

Ruan W, Shapiro-llan DI, Kaplan F, Lewis EE, Alborne H, Guf X, Schliekelmang P (2018) Movement patterns in entomopathogenic nematodes: continuous vs. temporal. J Invertebr Pathol 151:137-143

Shehata IE, Hammam MMA, El-Borai FE, Duncan LW, Abd-Elgawad MMM (2019) Comparison of virulence, reproductive potential, and persistence among local Heterorhabditis indica populations for control of Temnorhynchus baal (Coleoptera: Scarabaeidae) in Egypt. Egypt J Biol Pest Control 29:32. https:// doi.org/10.1186/s41938-019-0137-5
Torr P, Heritage S, Wilson M (2004) Vibrations as a novel signal for host location by parasitic nematodes. J Invertebr Pathol 34:997-999

Trdan S, Čuk J, Poženel A, Kralj MB, Rot M, Carlevaris B, Žežlina I, Vidrih M, Laznik $\check{Z}$, Bohinc T (2019) Field testing of different synthetic attractants for mass trapping of common European cockchafer (Melolontha melolontha [L.], Coleoptera, Scarabaeidae) adults, Acta Agric Scandinavica, Section B -Soil \& PI Sci 69:(2)174-180

White GF (1929) A method for obtaining infective nematode larvae from cultures. Science 66:302-303. https://doi.org/10.1126/science.66.1709.302-a

Wilson MJ, Gaugler R (2004) Factors limiting short-term persistence of entomopathogenic nematodes. J Appl Entomol 128:250-253

Wilson MJ, Lewis EE, Yoder F, Gaugler R (2003) Application pattern and persistence of the entomopathogenic nematode Heterorhabditis bacteriophora. Biol Cont 26:180-188

Woodring L, Kaya HK (1988) Steinernematid and heterorhabditid nematodes: a handbook of techniques. Arkansas Agricultural Experiment Station, Fayetteville, Arkansas. Series Bulletin 331

\section{Publisher's Note}

Springer Nature remains neutral with regard to jurisdictional claims in published maps and institutional affiliations.

\section{Submit your manuscript to a SpringerOpen ${ }^{\circ}$ journal and benefit from:}

- Convenient online submission

- Rigorous peer review

- Open access: articles freely available online

- High visibility within the field

- Retaining the copyright to your article

Submit your next manuscript at $\boldsymbol{\nabla}$ springeropen.com 